\title{
Bold First Ascent and Difficult Repeats: \\ A Study of Guides and Porters on Mount Kilimanjaro 探討登山挑夫的背境
}

\author{
Jimoh SHEHU \\ Department of Physical Education, \\ University of Botswana, BOTSWANA \\ 施 許 \\ 非洲波斯尼亞大學體育學系 \\ Hamad NDEE \\ Department of Physical Education, Sport \& Culture \\ University of Dar es Salaam, TANZANIA \\ 安狄 \\ 坦桑尼亞達斯沙林大學體育及文化學系
}

\begin{abstract}
This qualitative study examines the material conditions of youth serving as porters and guides to tourists making their ways across Mt Kilimanjaro. That mountaineering is a risky and onerous venture is well known. What is not often clear are the experiences of young school leavers who place their lives and limbs in jeopardy working as guides and porters. Yet this is a group whose jobs are increasingly complex, have multiple significances for the growth of mountain tourism and carry the potential to mask poverty and exclusion. As this study shows, it is neither the thrill of ascent nor the wages paid by tour operators that induce many youngsters to endure exposure to cold, back-breaking work and job insecurity - it is poverty. Since few people engage in mountaineering, mountain guides and porters are often considered to be a minority so small or so far beyond the realm of experience as to be a target of policy interventions. While effort is being made by policy makers to expand job real opportunities for the youthful segment of society, attention must also be paid to the problem of the working poor - represented in this study by the cooks, porters and guides on Mt. Kilimanjaro.
\end{abstract}

\section{摘 要}

本文旨在探討非洲年青人參與登山挑夫工作的原因,質性研究資料顯示貧窮是參與工作的動機.

\section{Introduction}

In the past two decades, international tourism has become increasingly central to Tanzania's socio-economic development. As a principal tourist destination, Tanzania offers famous attractions such as heritage sites and historic monuments, traditional cuisine, rituals and dances; abundant sunshine, oceanic pleasures and seaside resorts; abundant wildlife and flora, gigantic craters, indigenous cultures, exquisite handicrafts, as well as the highest mountain in Africa - Kilimanjaro. However, the growth of tourist trade and the development of infrastructure needed for 
tourist-related activity in Tanzania, as elsewhere, have been fueled by forces globalization. As noted by Mullins (1999): Contemporary tourism... is primarily the product of three major social forces. The first is the globalizing demands to consume as many goods and services as possible.... In addition to the tourists, who provide the demands for tourist products, two other groups contribute to urban tourism and tourism urbanization.... The first group includes those who manufacture, market and sell goods and services to tourists. Transnational corporations provide the leadership for the tourism industry, although local producers and merchants more likely to sell goods and services directly to tourists and thereby become important economic players in the game as well. Political actors use political means to control the rate and trajectory of development... (p.20)

Thus apart from the significant role of transnational corporations and global capitalism in tour packaging and merchandising and consumption, local people also play a part in the production of tourist goods and services such as food, entertainment, tours and shopping. However, the prevalent employment images that emerge from the literature on global tourism (see examples, Torkildsen, 2005; Judd \& Fainsten, 1999) coincide with post-Fordist, post-industrial changes in society: increasing diversity, networking, specialization, flexibility, fluidity, mòbility and change (Ball, 1994; Hutton, 1995; Castells, 2000).

This qualitative study examines the material conditions of youth serving as porters and guides to tourists making their ways across Mt Kilimanjaro. That mountaineering is a risky and onerous venture is well known. What is not often clear are the experiences of young school leavers who place their lives and limbs in jeopardy working as guides and porters. Yet this is a group whose jobs are increasingly complex, have multiple significances for the growth of mountain tourism and carry the potential to mask poverty and exclusion. As this study shows, it is neither the thrill of ascent nor the wages paid by tour operators that induce many youngsters to endure exposure to cold, back-breaking work and job insecurity - it is poverty. Since few people engage in mountaineering, mountain guides and porters are often considered to be a minority so small or so far beyond the realm of experience as to be a target of policy interventions. Worldwide, tourist industries are notorious as predominantly low-wage service sector (Economic Outlook, 2004; Judd \& Fainstein, 1999). Given the close connection between social and spatial mobility (Mabogunje, 1980), the geographical isolation of mountain guides and porters tend to impede their life chances and as such, the plights of these guides and porters needs to be taken into consideration in programs to eliminate poverty and transform society.

\section{Research Questions}

This study was designed to address a number of research questions, namely:

1. What are the job descriptions and patterns of earnings of mountain guides and porters with reference to gender and formal schooling?

2. How do these workers perceive the quality of their lives and the opportunity cost of being guides and porters?

3. What hazards are associated with portering and guiding and what are the welfare implications of these hazards?

4. What are the structural shifts in Kilimanjaro mountain tourism - job volatility, shocks, job fragmentation, and seasonality - and their effects on casual labor supply and demand?

\section{Methodology}

The methodology of this study was essentially qualitative. This approach was deemed appropriate for this study for reasons related to the research problem, the audience and the respondents. The research problem was essentially about the social, economic and livelihood experiences of mountain guides and porters and how these experiences impact on their quality of life. A problem like this demands a research process capable of yielding exploratory, detailed, holistic data, generated in a natural setting (Patton, 2000; Creswell, 2003). The primary audience for this study includes those who shape social policies intended to cater to the associated needs of youth in formal and informal labor markets. This primary audience needs in-depth, exploratory data about the unique and salient concerns of casual, low-paid workers in the tourism industry. Finally, mountain guides and porters constitute a population that has been previously under-researched in Tanzania and this suggest a need to understand the dynamics of their lived experiences and challenges in terms of patterns, themes and emergent information. 


\section{Sample}

Twenty-six of the participants interviewed for this study were drawn from the following fifteen tour companies: Zara, Dick-Dick, Kinyonge, Shidolia, A. A. Tours, Peacock Safari, Moon Safari, JMT Tours, Bobby Tours, Kilimanjaro Travelers, Tangayika Tours, A \& K, Keys Hotel, Real Adventure Tours, and African Walking Safari. Apart from these 26 participants, the study also included three freelance guides and seven freelance porters. The sampling was convenient, based on the number that accepted to participate in the study. The participants were born between 1975 and 1983, with their ages ranging from 21-29 years when this study was conducted. About $75 \%$ of those interviewed were KINAPA certified guides while the rest were porters. All the respondents had completed primary education and about $60 \%$ were secondary school leavers. About $30 \%$ had married by age 25 . On the average each participant had two children. At the time of this study, the participants were resident around Marangu Mtoni and Moshi town. About $10 \%$ of the respondents were females and all the study participants were citizens of Tanzania

\section{Data Collection}

The first phase of data generation entailed observation and interviewing of the guides and porters at the Marangu Gate of the Kilimanjaro National Park (KINAPA). This phase lasted seven days. The second phase involved a five-day hike through the mountain passes to the Gilman's Point $(5,685 \mathrm{~m})$. Recorded interviews took place along the way as well as during stop-over at Mandara, Horombo and Kibo huts - distances of 2720m, 3780m and $4750 \mathrm{~m}$, respectively. During the weeks of study over twenty formal interviews were conducted, coupled with numerous 'casual' conversations at the mountain hostel dining halls, water points, kitchens and stopovers along the way. Participants answered questions about their demographics, work experiences, anxieties, work strategies, health challenges, livelihood prospects and aspirations, job demands, gaps in their training, and financial situations. The participants were given an assurance of confidentiality. Number included in each open-ended interview varied from two to five individuals. Total interview times before the hike ranged from one to two hours, with the majority of the interviews during the ascent and descent lasting around 20-30 minutes, depending on the interviewees' convenience. This approach was in recognition of the respondents' responsibilities towards their clients.

\section{Data Analysis}

Transcription of the audio-taped interview as well as the extensive notes taken during each interview were reviewed several times, coded, categorized, interpreted and analyzed in terms of common themes (Patton, 2002; Creswell, 2003; Strauss \& Corbin, 1990). In presenting direct quotations from participants' narratives, names have been omitted to protect the confidentiality of information given during the research.

\section{Motivations and Job Descriptions}

Naturally, we explored the motivation of our respondents for becoming mountain guides and porters. For the participants, their jobs were not just tied to sustenance of livelihood but intertwined identity construction; notions of masculinity, social responsibility, cultural continuity, economic productivity and environmental sensitivity (see Table 1).

\section{Table 1. Occupational Motivations.}

- To supplement family income

- To enjoy the thrills of mountain hikes

- To practice our indigenous ways of life

- To sharpen my communication skills

- To set up a stepping stone to something better

- To extract financial benefits from the mountain

- To keep fit and live long

- To learn about the tour operation trade

- To earn a livelihood

- To become self-reliant

- To demonstrate market myself to potential employers amongst the tourists

- To escape poverty

- To sell our mountain ranges to the world

- To affirm my identity as a Kilimanjaro native

- To prove my worth as a man

- To work in a natural/idyllic environment

- To contribute to environmental conservation

- To build a network of foreign friends 
In the context of our findings, mountain tourism can be likened to a unit of production employing temporary workforce to produce fast and flexible runs of valueadded recreational services to a niche market of hikers and travelers. This production is based on a division of labor amongst various workers, including guides, assistant guides, porters and cooks. The production is facilitated by various physical and social resources such as thee climate, accessible tourist routes, differentiated accommodation, natural attractions and social amenities. Other critical factors include patronage of tourists, state intervention in terms of national security, political stability, and preservation of natural and cultural heritage. The organization, coordination and employment of the production workforce are specifically concentrated in the hands of tour operators, a guild responsible for seeking new markets for cultural and natural tourist attractions. Thus within the mountain tourism sector there is a clear separation between owners of capital and the laborers; and a social relation governed by criteria such as wages, exploitation, power hierarchy and interdependence. In terms of gradation of labor, the guide's experience, knowledge, skills and judgment are critical to the efficient management of the hiking expedition. However, the exigencies of guiding socially differentiated tourist through the wilderness encourage cooperative decision-making among the crew. During our field work we observed the work relations depicted in Table 2 among the expedition crew. The tabulated jobs often take place in a variety of locations, including the clients' hotels, KINAPA registration points, grocery shops, water points, kitchens, mountain trails, camping locations, mountain dormitories, dinning halls, loading points, halfway, points of departure and arrival, and areas of tourist attractions.

According to our respondents, the routes taken during ascent and descents contribute to how much work the crew has to perform. The various routes to climbing Mountain Kilimanjaro are Machame, Rongai, Marangu, Mbwe, Mweka, Lemosho and Londros. The generally perceived to be the most difficult is the Machame route due to the steepness and distance (about 8hrs trek from the gate to the first hut). Comparatively, the Marangu route was considered to be the friendliest, with three mountain huts along the way: Maandara $(2720 \mathrm{~m})$, Horombo (3780m) and Kibo (4750m).

Table 2. Division of Labor.

\begin{tabular}{|l|l|}
\hline Worker & \multicolumn{1}{|c|}{ Role } \\
\hline Guide & $\begin{array}{l}\text { Timetabling; making decisions regarding directions of expedition, camping, loading, } \\
\text { distribution of provisions and hazard prevention; ensuring appropriate clothing and } \\
\text { equipment utilization by tourists; making arrangements for medical help and emergency } \\
\text { rescue; providing running commentary on environmental and cultural attractions; sometimes } \\
\text { responsible for hiring of porters, cooks and purchase of food items. }\end{array}$ \\
\hline Assistant Guide & $\begin{array}{l}\text { Complementing the role of the guide, supporting the clients, providing for special needs } \\
\text { and helping sick clients to rescue points. }\end{array}$ \\
\hline Porter & $\begin{array}{l}\text { Carrying of clients' luggage, camping appliances, hiking equipment and water; assisting } \\
\text { with putting up and taking down of tents as well as in food preparation. }\end{array}$ \\
\hline Cook & $\begin{array}{l}\text { The porter designated as a cook is mainly responsible for catering to and meeting the } \\
\text { refreshment needs of clients and crew. Responsible for carrying kitchenware, cleaning, } \\
\text { washing and drawing of water. }\end{array}$ \\
\hline
\end{tabular}


Task timing, scarcity of water and extreme temperature also contribute to a greater work overload for the crew. For example, the last part of the climb to the summit is normally undertaken at midnight, requiring the guides and their assistants to weather extremely cold temperature to conduct the clients round the Uhuru Peak at altitudes above $5800 \mathrm{~m}$. Besides, there is no water after Horombo and so porters and cooks have to carry large quantity of water either through the Mawenzi path or the mountain saddle to the Kibo Hut.

\section{Gender Dimensions}

From the perspectives of our male respondents, portering and guiding reinforce a masculine ideology of self-reliance, bravery, strength and endurance, while for the females it is mostly about resourcefulness, independence, supplementation of family income and access to and management of cash. During our fieldwork, we observed that a typical female task was that of portering or cooking, an index of sexual division of labor. We gathered that there were about 15 female porters compared to hundreds of males working as porters and guides on the mountain. When we talked to the four females about experiences, they characterized their work in terms of:

\section{- Arduousness}

- Male domination of production processes

- Oversupply of workers

- Seasonality and casualization of labor

- Lack of vocational training,

- Low wages,

- Impossibility of combining two labor options on the mountain such as portering as well as cooking in order to earn double income

- Long absences from home

- Lack of control over pace of work, in terms of what to carry, how far and for how long.
Asked why there were few women porters or guides, the female respondents reply that it had to do with the following factors:

- Demands of childcare

- Housework

- Lore of masculinity that sees mountaineering as largely men's business

- Marriage

- Fear of molestation up mountain

- Cultural restrictions meant to protect women's sexual modesty and respectability

- Crowded living conditions for cooks and porters on the mountain

- Lack of information and fewer opportunities for women to train as guides

- $\quad$ Preference for male crew by clients and tour operators

The following quotes from the women's responses highlight their preoccupations:

'We need jobs- whether seasonal, part-time or casual to survive.'

'I have a husband who is also a porter. I need to support his irregular and meager earnings.'

'A woman needs control over some cash; portering gives me some financial empowerment.'

'Life is hard; a woman needs to supplement her housekeeping allowances.'

'Some of us are household heads for a number of reasons. We have to work to ensure familial welfare.'

'When you are a porter you generate income and reduce expenditure at the same time in the sense that we eat the leftovers of clients and save our wages until we get back home. Besides, there is nothing to be bought on the mountain anyway.'

'We often share leftover groceries and that helps us to reduce our expenditure on household provisions.' 


\section{Wage Structure}

As at the time of our fieldwork, the guiding and portering crews were paid wages ranging from $\$ 5-\$ 15$ per day and average of $\$ 20-\$ 60$ per expedition, depending on the days spent or distance covered by the client(s) (see Table 3).

Table 3. Minimum Wage.

\begin{tabular}{|lc|}
\hline Job Title & Daily Wage \\
Guide & $\$ 12-\$ 15$ \\
Assistant Guide & $\$ 10-\$ 12$ \\
Porter & $\$ 07-\$ 10$ \\
Cook & $\$ 05-\$ 07$ \\
\hline
\end{tabular}

It is worth noting that due to oversupply of labor and the seasonality of the job, it is quite common for most guides and porters to be employed for only five days in a month. That the guides command higher wages and more reputable status is attributable to their level of formal schooling, certification, English proficiency, experience, and possession of a license or permit - a pointer to differences in return to education. Apparently, completing the Wilderness Skills Module and obtaining a Guide's Permit provided a key benefit over and above primary or secondary education without additional certification by KINAPA. To be sure, no specific incentives are built in to the mode of wage payment noted above, but the extras often come in the forms of perks from the tourists. Our respondents said they always look forward to tips and gifts from their clients, and these often take the forms of:

- Cash in local currency

- Cash in foreign currency

- Gift of hiking and camping equipment

- Personal clothing/shoes/bags/drinking vessels

- Leftover groceries

- Financial pledges and other donations remitted from abroad
Thus, while returns to labor may be quite low, a porter's or guide's income may sometimes rise according to the bonuses received in cash and kind. Selling or using of these gift items help the recipients to supplement their income, accumulate capital, and reduce expenditure on hiking equipment.

\section{Perception of Quality of Life and Opportunity Cost of Portering/Guiding}

In our study we explored the perceived opportunity costs of portering and guiding and the extent to which working as guides or porters enhances or detracts from our respondents' quality of life. On the upside, the interviewees noted that the mountain tourism production processes are beneficial to both labor and capital as the locals find a ready demand for their skills and stamina while the tour operators are able too choose from a large pool of indigenous laborers, and are saved from the exertion and cost of recruiting workers from outside the locality. Their views are illustrated by the following:

'Competencies in tour guiding have made some difference in my life in terms of employability.'

'It is a hard way to survive - lugging heavy stuff across the mountain - but it is better than being left by the wayside, jobless and hopeless.'

'There is mobility, up and down, as between porters, guides and assistant guides due to experience and additional training and so one is able to have some social standing, however lowly.'

'Doing nothing day in, day out can make a man depressed or become a butt of village jokes, so I am a bit glad to have this chance to be a porter.'

On the flipside, however, those we interviewed were quick to point the opportunity cost of their work as illustrated by the following responses:

'It is hard to combine two or three labor options while climbing the mountain as one would do in the valley.'

While on the mountain better job opportunities might open up in the locality and these would have been taken by the time our expedition is over.'

'No leisure from the start of expedition to finish. It is tedious work all the way.'

'This job rarely opens up opportunities for new training or occupations outside mountain tourism.' 
'You cannot afford to fall ill in this job and still have your job waiting when you recover. Once you are sick, you down and out of that expedition.'

'You never know which group of clients would give a handsome tip. Some clients can be quite stingy and that can mean the difference between a worthwhile trip and an unfortunate one.'

'A client whose item is stolen or lost during a trip may get so mean and spiteful as to deny us the much needed bonus that porters and guides crave.'

'When clients forget personal items in any of the huts we are duty bound to go and fetch them at no extra payment.

'Those of us attached to tour companies do not receive any steady salaries as our employment is tied to availability of clients. No clients, no pay. Yet we are expected to hang around our company offices while missing out on possible employment elsewhere.'

'Freelance guides and porters do not enjoy the privilege of being kitted like their counterpart affiliated to tour companies.'

'We are often far away from home for up to five days or more. Thus during the hiking season we are like absentee parents or spouses.'

'Wages vary according to clients and companies. To accept a particular wage is to forego another, as one cannot afford to dilly-dally in this job. Competition is stiff. Too many job seekers willing to settle for any wage to make ends meet.'

'In this work, there is no opportunity for advance payments. We work first and get paid afterwards. This means that pressing domestic or personal financial matters cannot be tackled until after the expedition.'

'One consequence of working in this job is that one is cut off from news and events as there are no televisions, radios or internet on the mountain.'

'Those working as Safari tour guides have great opportunities to travel far and wide within Tanzania while we are stuck here trekking the same route perpetually.'

'It is not uncommon for an expedition to be cut short at the request of unfit clients and this often depresses our wages considerably.'

'We are mostly dependent on our relationships with tour operators, as they control access to the tourist market. They often take advantage of our desperations for employment that they readily set rates much lower than the average. The pretend they don't need us.'

\section{Work Hazards}

The scope of our study was expanded to include variables and dimensions of occupational health concerns of our interviewees. Analysis of the data revealed the main themes as mountain sickness and working condition: stress, insufficient sleep, skin rash, stomach upset and complaints such as strain, sprain, and bodily pain due to load shock and over-exposure to inclement weathers and mosquitoes. The following are illustrative of the common responses:

'It doesn't matter how long you have been at this job. I for one have been a guide for six years and each ascent to the mountain peak makes me feel terribly breathless, and groggy.'

'The commonest complaints you hear around here are nausea, back pain, toe numbness, should pain, knee pain and dizziness, blisters and bunions.'

'The weather is harsh on the skin and it can be quite chilly at night. Getting frostbitten is commonplace if one is not well shod or padded.'

'At sunrise we are at risk of being blinded by the glare of the snow. This is why we undertake the last leg of the hike at midnight so that we descend before the snow glare.'

'Too many mosquitoes along the way; quite often I sleep fitfully due to malaria fever.'

'Some tourists try to complete the hike in three days without proper acclimatization and we have no choice but to accede to their demands. Naturally when they take ill we have to tend to them until the KINAPA rescue team arrives. Caring for sick clients complicates our jobs and exposes us to body fluids such as vomit, sputum, phlegm, mucous, urine, blood and faeces.'

'To be frank, the back pain that I get from this job is affecting my sex life.'

'Irregularity of employment and low wages are also a health problem because without full and gainful employment one cannot lead a healthy and tolerable life.'

'The first aid treatment we receive when we are injured cannot treat let alone cure our work related injuries. Tour operators or clients should be made to settle medical bills arising out of our work hazards.'

'Some clients are chain smokers and we are forced to inhale their cigarette smoke indirectly, as we have to walk by their sides.'

'Ours is a case of increasing exposure without medical insurance. It is doubtful whether any insurer would entertain the idea of insuring mountain guides, porters or cooks.' 


\section{Structural Shocks and Shifts in Guidling and Portering Labor Market}

On the supply side, Kilimanjaro region offers a major national concentration of experienced guides and porter, forming the basis for a wide variety of tourist services. However, changes in the demand for mountain tourism and other structural shifts can alter the labor market slots for guides and porters. Depicted in Table 4 are the identified sources of shocks in the mountain tourism labor market.

\section{Table 4. Sources of Shocks.}

- Inclement weather

- High cost of buying or hiring hiking equipment

- Travel advisories and terrorism alerts dissuading tourists from coming to East Africa

- Demands for one-day hike which fetches little in terms of wages

- Tourist stinginess

- Abortion of trip due to tourist fatigue or sickness

- Hike in admission fees charged by KINAPA, which often scares away many potential tourists

- Lack of water supply at the Kibo dormitory

- Wage Fluctuation

- Cost of training as a guide and obtaining a permit

- Qualitative differences in amenities along different mountain paths

- Gender imbalance in recruitment

- Gender stratification that restricts women mostly to the roles of porters and cooks

- Delay in emergency evacuation

- Lack of counseling on risks and risk sharing strategies

- Dim prospects for first-entry career opportunities in mountain tourism.

- Wage fixing by tour operators on the problematic assumption that guides and porters receive regular supplementary tip from tourists. 


\section{Discussions}

To be sure, mountain tourism can facilitate the development of new products, skills and services and offer interesting career locally. However, it can also reinforce job insecurity, leakage of multiplier effects and economic vulnerability. As observed by Torkildsen (2005), jobs in the hospitality segment of tourism are seasonal, low paid and tend to attract young people. Accordingly, this qualitative study proposes a reading of mountain guiding and portering not just in terms of waged work and employment opportunities for local youthful population, but as metaphors for the contradictions and challenges that can emerge in social policies to reduce poverty. In this study we have extensively use thematized quotes from our participants to connect agency and structure with the processes of providing portering and guiding services on Mt Kilimanjaro. To most of our interviewees, Mt Kilimanjaro is not just a terrain on which their job is performed; the work and the mountain also provide them with a sense of identity and a means of self-representation. They are fully aware that while the mountain offers them some means of livelihood, the geographical location of their work is a metaphor for social and economic marginality. Ironically, their location on the mountain was also seen by many of them as a provisional escape from the plebian and obscure status that the society accords cleaners, cooks and drawers of water and carriers of load, involved as they are in the arduous task of lugging rucksacks across the mountain. To be sure some of our respondents also engage in subsistence agricultural production and exchange, combining those with seasonal labor as porters and guides, yet these jobs have not improved their material conditions in any meaningful manner.

While familiarity with the mountain ranges and paths has always been a virtual prerequisite for qualification as a mountain guide, this knowledge has not improved the odds of promotion into the guide status for the porters in this study, as these fellows lack O' Level qualifications and proficiency in English. Besides, most of our respondents who had trained as guides did so out of lack of self-knowledge, inadequate vocational guidance or skills, shortage of local opportunities for employment when they left secondary school, inability to proceed to higher education, or being ill-advised by casual acquaintance or peers. All evidence indicates that many young people aspire to guiding and portering than are such jobs available, but also that many bright and ambitious youth, failing to obtain work of their choice, find themselves working as porters, guides and cooks because they happen to live in a mountainous locality which the tourism industry constantly draw upon for its casual labor force, without providing further training and opportunities.

The guides in this study enjoy large net income advantages over the porters and cooks. Their earning advantages may be attributed to credentials, communication skills and the fact that guides have to go with the tourists all the way to the summit while the porters and cooks remain behind at the Kibo Hut. But besides these factors, the disadvantages o of porters and cooks can be attributed to the feminization of cooking and cleaning jobs in society - suggesting that wages in this sector depend on whether one was doing what is commonly labeled as women's work - labor of care, cooking, serving of meals, cleaning, picking and carrying of things (Parrenas, 2001; Meyer, 2000). It is this patriarchal ideology which clearly explains why virtually all our female respondents were porters - a position which puts them in inferior status in relation to the guides, the clients and male porters.

For the most part, tourist flow to Mount Kilimanjaro is seasonal and as such employment of guides is characterized by fragmented contracts of a few days or a week at most. The participants expressed concern about oversupply of youth and adult labor. Our data revealed that porters and cooks were disadvantaged in three ways. First, their lack of certification restricted them to blindalley jobs. Second, they were not unionized; and third, with a big reservoir of labor competing for work, porters and cooks often undercut each other by settling for pittance. Although the guides are unionized, for the most part wage bargaining is an individual matter.

Clearly, exposure of the Kilimanjaro area to the world tourism market has created a complex web of relations linking casually employed porters, guides and cooks with the leisure class, foreigners, and capitalists, creating new forms of inequality and power relations. In other words, globalization has linked mountain porters and guides with clients from all over the world, but it has also impacted on the wages, well-being, work and livelihoods of these casual laborers through wage depression, exchange fluctuation, unstable tourist traffic, 
distortions in the consumption of mountain-based attractions and lack of equitable redistribution of tourism revenue. Significantly, casual employment has failed to offer our respondents a rout to self-sufficiency and has in fact created awareness of social isolation and in some instances a sense of being trapped on the edge of society.

\section{Conclusions and Policy Implications}

While mountain tourism has generated enormous wealth for the Tanzanian government and tour companies, it has not significantly enhanced the livelihood of porters and guides who were the focus of this study. Rather, growing job insecurity, industrial volatility and casualization of low-wage works are creating disturbing trends that keep these workers below poverty line. Another factor contributing to the pauperization of porters and guides is the way their work generate stress, alienation and myriads of muscular, neurological, dermatological and cardiovascular illnesses. Although we noted a disparity between the wages of Kilimanjaro mountain guides and porters, the fact that the guides are certificated and licensed has not protected them from temporary and contingent employment. There are just too many porters and guides in Kilimanjaro area persistently seeking to work, and struggling for a foothold on the employment ladder, with some gaining and most losing in their efforts to contribute to the welfare of their poverty-level households. While effort is being made by policy makers to expand job real opportunities for the youthful segment of society, attention must also be paid to the problem of the working poor represented in this study by the cooks, porters and guides on Mountain Kilimanjaro. These workers need guidance and counseling, decent wages; supplemental education in entrepreneurship and enterprise development; legal advise; medical insurance; socially inclusive and gender sensitive working environment; vibrant unionization; and poverty alleviation interventions.

\section{Acknowledgements}

1. This report grew out of a research funded by the University of Dar es Salaam Research and Publication Committee in 2004. The authors are grateful to the URPC for financial assistance.

2. The first part of the title of this paper is a phrase invented by The American Alpine Club (http:// alpineclub.advantrics.com). Although the phrase was originally used in the context of Lyman Spitzer Climbing Grant advertisement, we believe the connotation of the phrase aptly prefaces the experiences and challenges discussed in this article.

\section{References}

Ball, S. (1994), Education Reform: A Critical and Postcolonial Approach. London: Open University Press.

Castells, M. (2000). The Information Age - Economy, Society and Culture. Oxford: Blackwell.

Cresswell, J. (2003). Research Design: Qualitative, Quantitative, and Mixed Method Approaches. Thousand Oaks, CA: Sage Publications.

Economic Outlook 2004: Santa Barbara County. (2004). Santa Barbara: UCSB Economic Forecast Project.

Hutton, W. (1995). The State We Are In. London: Jonathan Cape.

Judd, D.R., \& Fainstein, S.S. (1999). (Eds.). The Tourist City. New Haven, CT: Yale University Press.

Mabogunje, A.L. (1980). The Development Process: A Spatial Perspective. London: Hutchinson.

Meyer, M. H. (2000). (Ed.). Care Work: Gender, Labor and the Welfare State. New York: Routledge.

Mullins, P. (1999). International Tourism and the Cities of Southeast Asia. In: The Tourist City, Judd, D.R. \& S.S. Fainstein (Eds.). New Haven, CT: Yale University Press. pp. 245-260. 
Parrenas, R.S. (2001). Servant of Globalization: Women, Migration and Domestic Work. Stanford: Stanford University Press.

Patton, M. (2002). Qualitative Research and Evaluation Methods. Thousand Oaks, CA: Sage Publications.

Strauss, A., \& Corbin, J. (1990). Basics of Qualitative Research: Grounded Theory Procedures and Techniques. Thousand Oaks, CA: Sage.

\section{Correspondence}

Jimoh Shehu, Ph.D.

Department of Physical Education

University of Botswana

Private Bag 0022

\section{Gaborone}

Botswana

E-mail: shehu@mopipi.ub.bw

Hamad Ndee, Ph.D.

Department of Physical Education, Sport \& Culture University of Dar es Salaam

P. O. Box 35048

Dar es Salaam

Tanzania

E-Mail: hndee@yahoo.co.uk 